\title{
Association of Systemic Anaplastic Large Cell Lymphoma and Active Toxoplasmosis in a Child
}

\author{
Shirin Sayyahfar, ${ }^{1}$ Abdollah Karimi, ${ }^{2, *}$ Atoosa Gharib, ${ }^{3}$ and Alireza Fahimzad ${ }^{2}$ \\ ${ }^{1}$ Department of Paediatrics, Ali Asghar Children Hospital, Iran University of Medical Sciences, Tehran, IR Iran \\ ${ }^{2}$ Paediatric Infection Research Centre, Shahid Beheshti University of Medical Sciences, Tehran, IR Iran \\ ${ }^{3}$ Department of Pathology, Imam Hosein Hospital, Shahid Beheshti University of Medical Sciences, Tehran, IR Iran \\ ${ }^{*}$ Corresponding author: Abdollah Karimi, Paediatric Infection Research Centre, Shahid Beheshti University of Medical Sciences, Tehran, IR Iran. Tel: +98-2122226941, Fax: +98-2122227033, \\ E-mail:dr_akarimi@yahoo.com
}

Received: July 6, 2015; Accepted: July 11, 2015

Introduction: Anaplastic large cell lymphoma is a subset of non-Hodgkin lymphoma and an unusual disease in children.

Case Presentation: Herein we have reported a 7- year- old girl with a large necrotic skin ulcer on the chest caused by systemic form of anaplastic large-cell lymphoma and simultaneous active toxoplasmosis diagnosed by PCR on lymph node specimen. There were few reports showing a role for toxoplasma infection to cause some malignancies such as lymphoma in adults.

Conclusions: Based to our knowledge, this has been the first report of simultaneous systemic anaplastic large cell lymphoma and active toxoplasmosis, documented by positive PCR on tissue biopsy in a child. This case report has suggested more attention to the accompanying Toxoplasma gondii infection as a probable cause of some types of lymphomas.

Keywords: Anaplastic Large-Cell Lymphoma; Non-Hodgkin Lymphoma; Toxoplasmosis

\section{Introduction}

Anaplastic large cell lymphoma (ALCL) or Ki-1 lymphoma is a subset of non-Hodgkin lymphoma and an unusual disease in children accounting for $10 \%-15 \%$ of all childhood non-Hodgkin lymphomas (1-3).

This disease is a $\mathrm{T}$ or null cell lymphoma characterized by proliferation of pleomorphic large neoplastic lymphoid cells which express the CD30 antigen (Ki-1 antigen) (1-4). There are few studies about the role of Toxoplasma gondii infection in the pathogenesis of lymphoma in adults (5).

Herein we have reported a 7-year-old girl with a large necrotic ulcer, simultaneous active toxoplasmosis and final diagnosis of systemic form of ALCL. Based to our knowledge, this is the first report of simultaneity of ALCL and active toxoplasmosis in a child.

\section{Case Presentation}

A 7-year-old girl was referred to Mofid Children's Hospital with a large necrotic ulcer on his left upper chest, and generalized lymphadenopathy since two months ago (Figure 1).

The ulcer was begun with a small pruritic papule on the left upper chest, enlarged and extended to the neck, and then ulcerated.

She had a history of toxoplasmosis presenting with cer- vical lymphadenopathy, and positive IgM and IgG antitoxoplasma antibodies, at least 10 months before this ulcer appearance. An excisional biopsy was performed at that time, with result of preserved nodal architecture, follicular hyperplasia and no malignant cells and positive PCR for Toxoplasma gondii infection, so, she underwent following up until the skin ulcer appeared, and then, she was referred for more extensive work up.

On physical examination she had a large necrotic ulcer $(20 \times 10 \mathrm{Cm})$ with a noma appearance on the chest, and a hyperpigmented plaque $(2 \times 1 \mathrm{~cm})$ on the abdomen, along with generalized lymphadenopathy and mild splenomegaly.

After debridement of the chest wall ulcer and biopsies of abdominal skin and cervical lymph node, she was treated with ceftriaxone and clindamycin.

Several aerobic and anaerobic microorganisms such as Staphylococcus saprophyticus, Lactobacillus spp., enterococci spp., Staphylococcus aureus and Peptococus niger were isolated from the ulcer culture.

Further investigation showed normal bone survey and bone marrow aspiration.

Thoracic computed tomography (CT) without contrast revealed a large lobulated mass in the left anterior chest wall, with extension to the axillary area and several

Copyright (C) 2015, Iranian Journal of Cancer Prevention. This is an open-access article distributed under the terms of the Creative Commons Attribution-NonCommercial 4.0 International License (http://creativecommons.org/licenses/by-nc/4.0/) which permits copy and redistribute the material just in noncommercial usages, provided the original work is properly cited. 


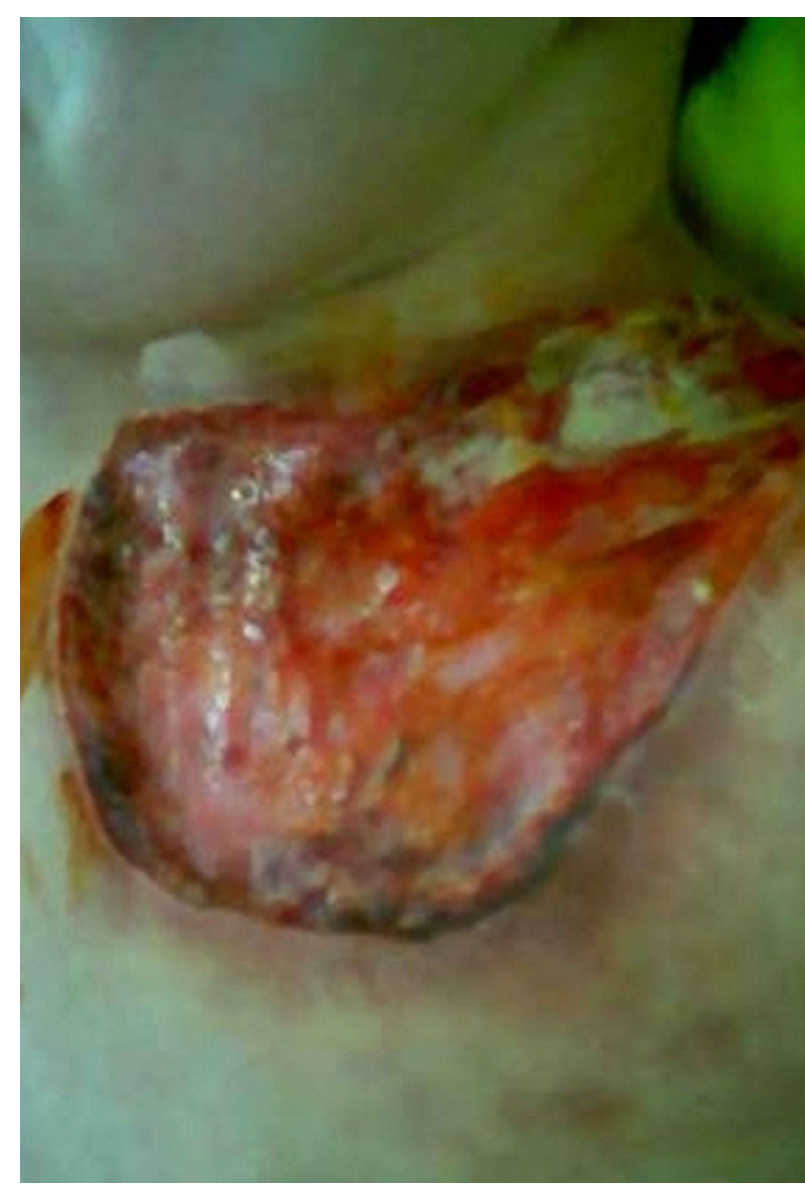

Figure 1. A large Necrotic Ulcer $(20 \times 10 \mathrm{Cm})$ on the Left Upper Chest of the Patient With a Normal Appearance

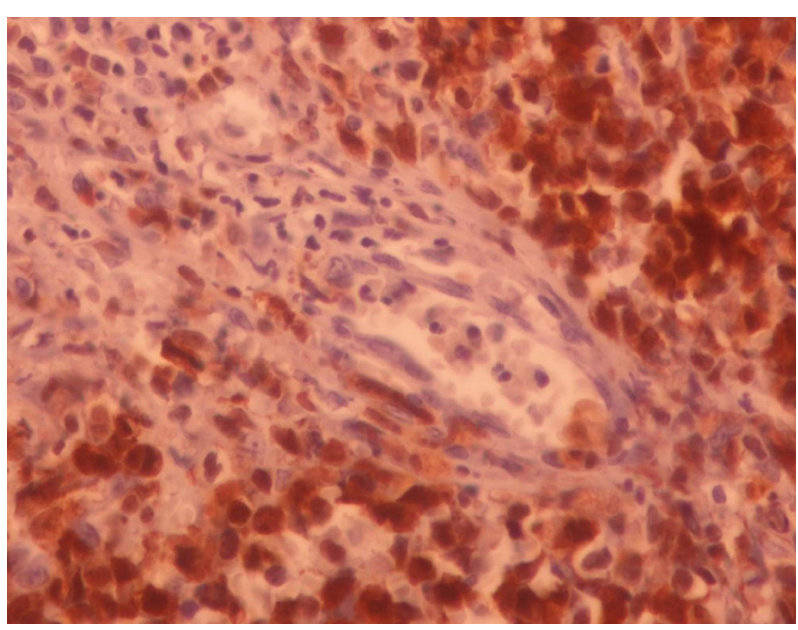

Figure 2. Cohesive Sheets of Relatively Monomorphic Atypical Cells With Round Vesicular Nuclei (H \& E, × 400)

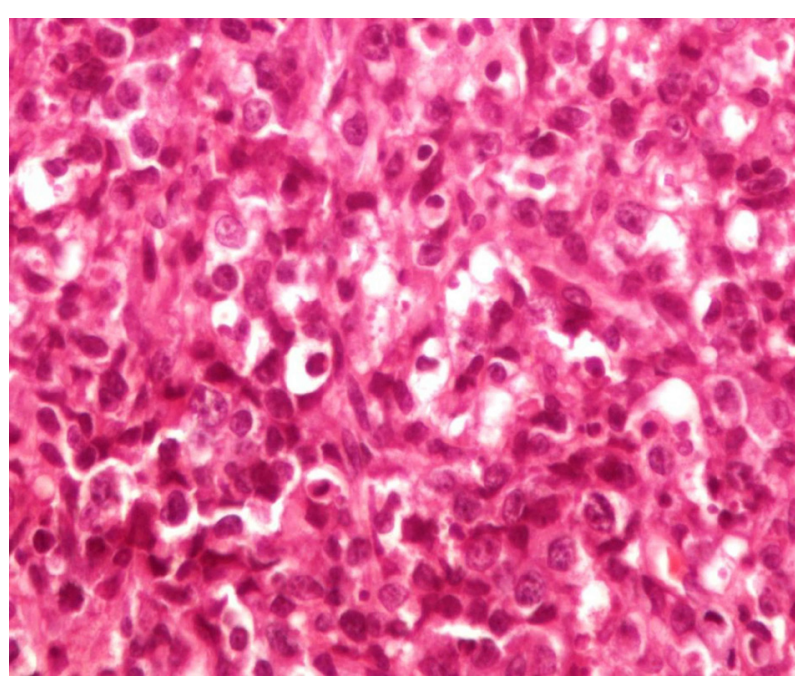

Figure 3. Positive Immunostaining of Perivascular Neoplastic Cells for $\operatorname{ALK}(\times 400)$

cervical and left supra clavicular lymphadenopathies. (The CT scan was not available in this article). Abdominal and pelvic CT scan revealed mildly enlarged spleen and para-aortic lymphadenopathies.

CT scan of the neck showed multiple extensive adenopathies predominantly in the left side of the neck and significant soft tissue swelling of the lower neck and chest wall. Brain CT scan was normal.

Routine laboratory tests were within normal ranges. Specific anti-toxoplasma antibody was detected by indirect immunofluorescent assay (IFA), shown a titre of 1:6400.

HIV test was negative. Biopsies of cervical lymph node, abdominal skin plaque and chest wall ulcer debridement were compatible with anaplastic large cell lymphoma (Figure 2). Immunohistochemical staining of cervical lymph node biopsy revealed tumour cells to be positive for leukocyte common antigen (LCA), ALK, CD30, CD3 and weakly positive for epithelial membrane antigen (EMA) (Figure 3). The second time PCR for Toxoplasma gondii was positive in the lymph node specimens. The patient underwent chemotherapy according to oncologist recommendations. Two years follow up has shown no relapse or major complications.

\section{Discussion}

ALCL has known as a distinct subset of non- Hodgkin lymphoma, accounted for $10 \%-15 \%$ and $2 \%-8 \%$ of nonHodgkin lymphomas in children and adults, respectively $(1,3)$. It had two major systemic and primary cutaneous forms.

Primary cutaneous ALCL accounts for approximately 9\% of cutaneous lymphomas and arises de novo in the skin. Patients with this forms of ALCL are generally older than 
patients with the systemic form of ALCL with a median age of approximately 60 years $(3,6)$. Its major difference from systemic type is the absence of the ALK protein (6).

The ALK protein is a fusion protein produced by a genetic translocation most commonly $\mathrm{t}(2 ; 5)$ involving the ALK gene on chromosome 2 and the nucleophosmine (NPM) gene on chromosome 5(3). ALK expression is present in $30 \%-60 \%$ of ALCLs and but is not present in normal lymphoid tissues (7).

Systemic ALCL is more frequent than primary cutaneous form and more common in the first three decades of life. Although systemic type could involve lymph nodes in more than $90 \%$ of the time, extra nodal involvement including skin (25\%), lung (10\%), bone (17\%) and liver (8\%) is also frequent (3).

Systemic type with cutaneous spread must be distinguished from Primary cutaneous ALCL because the former is an aggressive disease which necessitates multiagent systemic chemotherapy. Conversely primary cutaneous ALCL has 90\% - 100\% five years survival so immunostainig for ALK should be performed (7).

The diagnosis of our patient was $\mathrm{ALK}^{+}$systemic ALCL according to the positivity of tumor cells for ALK protein.

Natural killer cells are considered to play a role in the regulation of hematopoietic cells' activity in thymus and bone marrow, so infection with Toxoplasma gondii might decrease host immune response against tumor cell growth and predispose the patient to non-Hodgkin lymphoma $(8,9)$. Some studies on mice infected with Toxoplasma gondii showed decreased natural killer cell activity and changed thymic architecture. On the other hand toxoplasmosis (primary infection or secondary reactivation of latent infection) might be a complication of lymphoma, especially Hodgkin lymphoma, following impaired cell immunity (10). So, existence of an occult lymphoma before the appearance of signs and symptoms of toxoplasmosis is another explanation for our patient's presentation, although the normal lymph node biopsy, chest x-ray and abdominal ultra sound examination results of ten months before presentation of ALCL are against this hypothesis. Anyhow whether toxoplasmosis is a predisposing factor for lymphoma needs more investigations.

\section{Conclusions}

Necrotizing skin ulcer could be one of the manifestations of malignancies in children. In addition, according to our report and few other studies, there might be a role for toxoplasma infection to cause some malignancies such as lymphoma so it is suggested to set up some studies to compare the rate of toxoplasma infection in patients suffered from lymphoma and normal population in children.

\section{Acknowledgment}

none declared

\section{Authors' Contributions}

Shirin Sayyahfar designed and wrote wrote the first draft of this paper. All authors contributed to the intellectual content and approved the final version. Abdollah Karimi is the guarantor.

\section{Conflict of Interest}

The authors have no conflict of interest in this study.

\section{Financial Disclosure}

The authors have no financial disclosure in this study.

\section{References}

1. Tilly H, Gaulard P, Lepage E, Dumontet C, Diebold J, Plantier I, et al. Primary anaplastic large-cell lymphoma in adults: clinical presentation, immunophenotype, and outcome. Blood. 1997;90(9):3727-34.

2. Le Deley MC, Reiter A, Williams D, Delsol G, Oschlies I, McCarthy $\mathrm{K}$, et al. Prognostic factors in childhood anaplastic large cell lymphoma: results of a large European intergroup study. Blood. 2008;111(3):1560-6

3. Lowe EJ, Sposto R, Perkins SL, Gross TG, Finlay J, Zwick D, et al. Intensive chemotherapy for systemic anaplastic large cell lymphoma in children and adolescents: final results of Children's Cancer Group Study 5941. Pediatr Blood Cancer. 2009;52(3):335-9.

4. Jaffe ES, Harris NL, Stein H. World Health Organization Classification of Tumours: Pathology and genetics of Tumors of Haematopoettic and Lymphoid Tissues. Lyon: IARC Press; 2001.

5. Thirugnanam S, Rout N, Gnanasekar M. Possible role of Toxoplasma gondii in brain cancer through modulation of host microRNAs. Infectious Agents and Cancer. 2013;8(1):8.

6. Stein H, Foss HD, Durkop H, Marafioti T, Delsol G, Pulford K, et al CD30(+) anaplastic large cell lymphoma: a review of its histopathologic, genetic, and clinical features. Blood. 2000;96(12):3681-95.

7. Greer JP.T Cell and NK Cell Lymphoproliferative Disorders. Hematol. 2001;2001(1):259-81.

8. Kamiyama T. Toxoplasma-induced activities of peritoneal and spleen natural killer cells from beige mice against thymocytes and YAC-1 lymphoma targets. Infect Immun. 1984;43(3):973-80.

9. Kamiyama T, Tatsumi M. Effect of Toxoplasma infection on the sensitivity of mouse thymocytes to natural killer cells. Infect Immun. 1983;42(2):789-95.

10. Dudley NJ, Balfour AH. Non-Hodgkin's lymphoma presenting as 'chronic active toxoplasmosis'. Postgraduate Medical Journal. 1988;64(757):883-5. 